\title{
PENGEMBANGAN MODUL BERBASIS STEM (SCIENCE, TECHNOLOGY, ENGINEERING AND MATHEMATICS) PADA MATERI SIFAT KOLIGATIF LARUTAN
}

\author{
Fazlina Arisya *, Sri haryati, Betty Holiwarni.
}

Program Studi Pendidikan Kimia, Fakultas Keguruan dan Ilmu Pendidikan Universitas Riau, Kampus Binawidya KM 12,5, Pekanbaru 28293, Riau, Indonesia.

\begin{tabular}{l}
\hline \multicolumn{1}{c}{ Informasi Artikel } \\
\hline Sejarah Artikel: \\
Diterima: 16-07-2020 \\
Disetujui : 14-01-2021 \\
Dipublikasikan: 27-01-2021 \\
\hline Keywords: \\
Modul, \\
STEM learning, \\
colligative nature of \\
solution, \\
Reasearch and development.
\end{tabular}

A b s t r ak

Penelitian bertujuan untuk mengembangkan modul berbasis STEM pada materi sifat koligatif larutan kelas XII SMA/MA sederajat. Jenis penelitian merupakan penelitian dan pengembangan dengan model pengembangan 4D yang meliputi fase Pendefenisian, Perancangan, Pengembangan dan Penyebaran. Penelitian ini dilakukan sampai pada fase pengembangan (develop) berupa uji coba satu-satu, dan uji coba terbatas pada guru. Penelitian ini dilaksanakan di FKIP Universitas Riau, MAN 1 Pekanbaru dan SMA Cendana Pekanbaru. Objek pada penelitian ini berupa Modul dengan berbasis STEM. Teknik analisis data yang dipakai dalam penelitian ialah analisis statistik deskriptif, dilakukan dengan cara menghitung skor yang diperoleh pada saat validasi. Penilaian aspek kelayakan modul oleh tim validator berupa aspek kelayakan isi, karakteristik STEM, kebahasaan, penyajian, dan kegrafisan berturut turut memiliki skor $80 \%, 87,5 \%, 80,205 \%, 90,625 \%$, dan 91,25\%. Jadi, secara keseluruhan skor rata - rata validasi modul sifat koligatif larutan berbasis STEM adalah $85,916 \%$ termasuk dalam kriteria kelayakan valid, artinya modul yang dikembangkan layak untuk diuji coba secara terbatas sedangkan pada respons guru terhadap modul mendapatkan persentase $92,1 \%$ berada pada kriteria baik.

\section{A b s tract}

This research is aimed to develop modules based on STEM on the colligative properties of class XII SMA / MA. This type of research is research and development $(R \& D)$ with a $4 D$ model that includes the phases of Define, Design, Develop and Diseminate. The developed research was carried out until the development phase (develop) in the form of one-on-one trials, and trials were limited to teachers. This research was fully conducted at FKIP Riau University, MAN 1 Pekanbaru and Cendana Pekanbaru High School. The data analysis technique used in the study was descriptive statistical analysis, carried out by calculating the score obtained at the time of validation. The evaluation of module feasibility aspects by the validator team in the form of content eligibility, STEM characteristics, linguistic, presentation, and graphic characteristics have scores of $80 \%, 87.5 \%, 80.205 \%, 90.625 \%$, and $91.25 \%$, respectively. Overall the average score of the validation modules of the STEM-based solution was $85.916 \%$ included in the validity 
eligibility criteria, meaning that the module developed was eligible to be tested on a limited basis whereas the teacher's response to the module getting a percentage of $92.1 \%$ in good criteria.

(C) 2021 JPK UNRI. All rights reserved

*Alamat korespondensi:

e-mail: fazlina.arisyaa @gmail.com

No. Telf: -

\section{PENDAHULUAN}

Pendidikan merupakan suatu kebutuhan yang sangat diperlukan oleh semua manusia di seluruh dunia. Agar menjadi sumber daya manusia yang handal dan berkualitas, seseorang harus memiliki kecakapan abad 21 antara lain : 1) keterampilan belajar dan berinovasi yang meliputi berpikir kritis dan mampu menyelesaikan masalah, kreatif dan inovatif, serta mampu berkomunikasi dan berkolaborasi; 2) terampil untuk menggunakan media, teknologi, informasi, dan komunikasi; 3) kemampuan untuk menjalani kehidupan dan karir, meliputi kemampuan beradaptasi, luwes, berinisiatif, mampu mengembangkan diri, memiliki kemampuan sosial dan budaya, produktif, dapat dipercaya, memiliki jiwa kepemimpinan, dan tanggung jawab (Yuningsih, 2019; Martini, 2018).

Dalam pembelajaran kimia, kualitas pembelajaran dan ketercapaian tujuan pembelajaran sangat dipengaruhi oleh beberapa faktor, salah satunya yaitu penggunaan bahan ajar. Melalui bahan ajar guru dan peserta didik akan lebih mudah dan terbantu dalam melaksanakan proses pembelajaran. Bahan ajar yang dapat dikembangkan oleh guru salah satu diantaranya adalah modul. Modul merupakan alat atau sarana pembelajaran yang berisi materi, metode, batasan, dan cara mengevaluasi yang dirancang secara sistematis dan menarik untuk mencapai kompotensi yang diharapkan sesuai dengan tingkat kompleksitasnya (Utami et al. 2018; Depdiknas, 2018). Di samping itu, modul merupakan sebuah karya ilmiah yang ditulis dengan tujuan untuk memudahkankan peserta didika belajar secara mandiri dengan sedikit bantuan guru (Depdiknas, 2008). Pengembangan modul selaras dengan tuntutan kurikulum 13 yaitu tuntutan peserta didik untuk menjadi manusia seutuhnya yang berkarakter dalam dimensi hati, pikiran, raga, serta rasa dan karsa. Disamping itu, masih banyak sekolah yang belum menghasilkan modul pembelajran. Untuk itu, diperlukan penggembangan modul dengan karakter tertentu untuk dapat membimbing peserta didik untuk berkarakter positif (Viorita et al 2019). Salah satu modul yang digunakan untuk pembelajaran yang bersifat karakterisitk dan inovatif ialah pembelajaran STEM. Maka dapat dibuat suatu bahan ajar berupa modul berbasis STEM. Modul berbasis STEM (Science, Technology, Enginerring and Mathematics) adalah modul yang mengintegrasikan disiplin ilmu terkait. Pembelajaran bidang eksakta Sains, Teknologi, Teknik dan Matematika dapat terjadi (Utami et al. 2018).

Penelitian pengembangan modul berbasis STEM pada pokok bahasan sifat koligatif larutan untuk kelas XII SMA/MA menggunakan model pengembangan $4 D$ yang terdiri dari define (pendefenisian), design (perancangan), develop (pengembangan) dan disseminate (penyebaran). tahap disseminate (penyebaran) tidak dilakukan karena tujuan penelitian dibatasi hingga diperolehnya luaran berupa produk yang valid berdasarkan aspek kelayakan isi, kebahasaan, penyajian,kegrafisan dan karakteristik STEM, melalui penilaian oleh validator menggunakan lembar validasi yang merujuk pada panduan pengembangan bahan ajar menurut Badan Standar Nasional Pendidikan (2006).

Beberapa penelitian yang secara konferehensif mendiskusikan tentang pembelajaran berbasis STEM. Utami, et al (2018) telah mengambangkan modul matematika dengan pendekatan STEM pada materi segiempat memperoleh skor rata-rata persentase sebesar $87 \%$ dengan kriteria sangat layak. Hasil validasi ahli media memperoleh skor persentase sebesar $89 \%$ dengan kriteria sangat layak dan validasi ahli bahasa dengan persentase $92 \%$ dengan kriteria sangat layak. Respons peserta didik memperoleh persentase $87 \%$ pada uji coba lapangan dengan kriteria sangat menarik dan respons guru 
sebesar 90\% dengan kriteria sangat menarik. Modul ini membantu peserta didik dalam menjalankan sebuah proses untuk menemukan suatu konsep pemahaman matematika dengan mudah dan membantu peserta didik untuk lebih mengembangkan ilmu yang dimiliki di dunia nyata. Sugianto et al., (2018) telah melaporkan tentang pengembangan modul IPA berbasis STEM pada materi tekanan dan dikembangkan dengan menggunakan model analisis, perancangan, pengembangan, implementasi dan evaluasi (ADDIE). Temuan kajian ini diperoleh bahwa respons siswa dan guru terhadap modul yang dikembangkan dengan penilaian kategori sangat baik. Penelitian lain juga telah mengembangkan modul pembelajaran berbasis STEM seperti diimplementasikan pada materi larutan penyangga (Tripripa et al., 2020), kearifan lokal beduk untuk meningkatkan kemampuan berpikir kreatif siswa (Almuharomah et al., 2019) dan STEM diterapkan pada materi elektrokimia (Syahirah et al., 2020).

Berdasarkan pemaparan di atas, maka peneliti tertarik untuk melakukan penelitian pengembangan bahan ajar berupa Pengembangan Modul Berbasis STEM pada materi Sifat koligatif larutan untuk kelas XII SMA/MA sederajat.

\section{METODE PENELITIAN}

Jenis penelitian yang digunakan adalah penelitian pengembangan modul berbasis STEM SMA/MA sederajat kelas XII pada materi sifat koligatif larutan dirancang menggunakan desain penelitian dan pengembangan (Research and Development) dengan model 4-D. Tahapan 4-D ini terdiri dari empat tahapan yaitu pendefinisian, perancangan, pengembangan dan diseminate (Trianto, 2012). Penelitian pengembangan dengan model 4-D dipilih karena cocok untuk mengembangkan perangkat pembelajaran dan juga tahapan-tahapan pengembangannya sederhana dan mudah dipahami. tahapan pada desain penelitian dan pengembangan 4-D hanya dilakukan sampai pada tahapan pengembangan (develop) saja dikarenakan tujuan dari penelitian hanya mengembangkan modul yang valid dan mengetahui respons guru bidang studi kimia untuk mendapatkan kelayakan berdasarkan uji kelayakan isi, uji kebahasaan, sajian, kegrafisan dan juga aspek karakteristik STEM itu sendiri. Penelitian dilaksanakan di program studi Pendidikan Kimia FKIP UR dengan uji coba terbatas di MAN 1 Pekanbaru dan SMA Cendana Pekanbaru dengan waktu penelitian mulai bulan Maret-Juli 2020.

Teknik pengumpulan data dalam penelitian ini adalah dengan memberikan instrumen validitas kepada 3 orang validator yang akan menilai lima aspek kelayakan Modul, yaitu Kelayakan Isi, Kelayakan karakteristik STEM, Kelayakan kebahasaan, kelayakan penyajian dan kelayakan kegrafisan serta angket respons pengguna kepada guru yang dilakukan pada MAN 1 Pekanbaru dan SMA Cendana Pekanbaru. Data yang dihasilkan menjadi data yang diolah oleh peneliti sehingga didapat hasil analisis data. Alur Pengembangan Modul Sifat Koligatif Larutan Berbasis STEM ditunjukkan pada Gambar 1.

Modul yang telah valid, di ujicoba satu - satu kepada 3 orang peserta didik yang bertujuan untuk mengidentifikasi dan menghilangkan kesalahan dalam produk dan memperoleh informasi tentang reaksi pengguna terhadap materi dan pesan yang ingin disampaikan oleh produk (Modul) tersebut. Teknik analisis data yang dipakai dalam melakukan penelitian yaitu analisis statistik deskriptif, yaitu dengan cara menghitung rata - rata dari setiap aspek penilaian yang terdapat pada lembar validasi modul berbasis STEM pada materi asam basa. Rumus yang digunakan adalah persamaan 1:

$$
R=\frac{f}{n} \times 100 \%
$$

Di mana, $\mathrm{R}$ adalah persentase skor alternatif pernyataan sikap positif (\%), $\mathrm{f}$ ialah jumlah nilai yang diperoleh dan $\mathrm{n}$ adalah jumlah nilai maksimum. Kriteria dalam mengambil keputusan untuk 
validasi modul dapat dilihat pada Tabel 1. Modul dapat digunakan jika penilaian rata-rata validator dikategorikan baik dan sangat baik. Kriteria respons pengguna dapat dilihat pada Tabel 2.

Tabel 1. Kriteria Validitas

\begin{tabular}{lcc}
\hline No & Nilai (\%) & Keterangan \\
\hline 1 & $80.00-100.00$ & Baik/Valid/Layak \\
2 & $60.00-79.99$ & Cukup Baik/Cukup Valid/Cukup Layak \\
3 & $50.00-59.99$ & Kurang Baik/Kurang Valid/Kurang Layak \\
4 & $0.00-49.99$ & Tidak Baik (Diganti) \\
5 & & \\
\hline
\end{tabular}

Tabel 2. Kriteria Respons Pengguna

\begin{tabular}{ccc}
\hline No & Skor $(\boldsymbol{\%})$ & Kriteria Respon Pengguna \\
\hline 1 & $\mathbf{7 5 . 0 0 - 1 0 0 . 0 0}$ & Sangat Baik \\
2 & $\mathbf{5 0 . 0 0}-\mathbf{7 4 . 9 9}$ & Baik \\
3 & $\mathbf{2 5 . 0 0 - 4 9 . 9 9}$ & Kurang Baik \\
4 & $\mathbf{0 . 0 0 - 2 4 . 9 9}$ & Tidak Baik \\
\hline
\end{tabular}

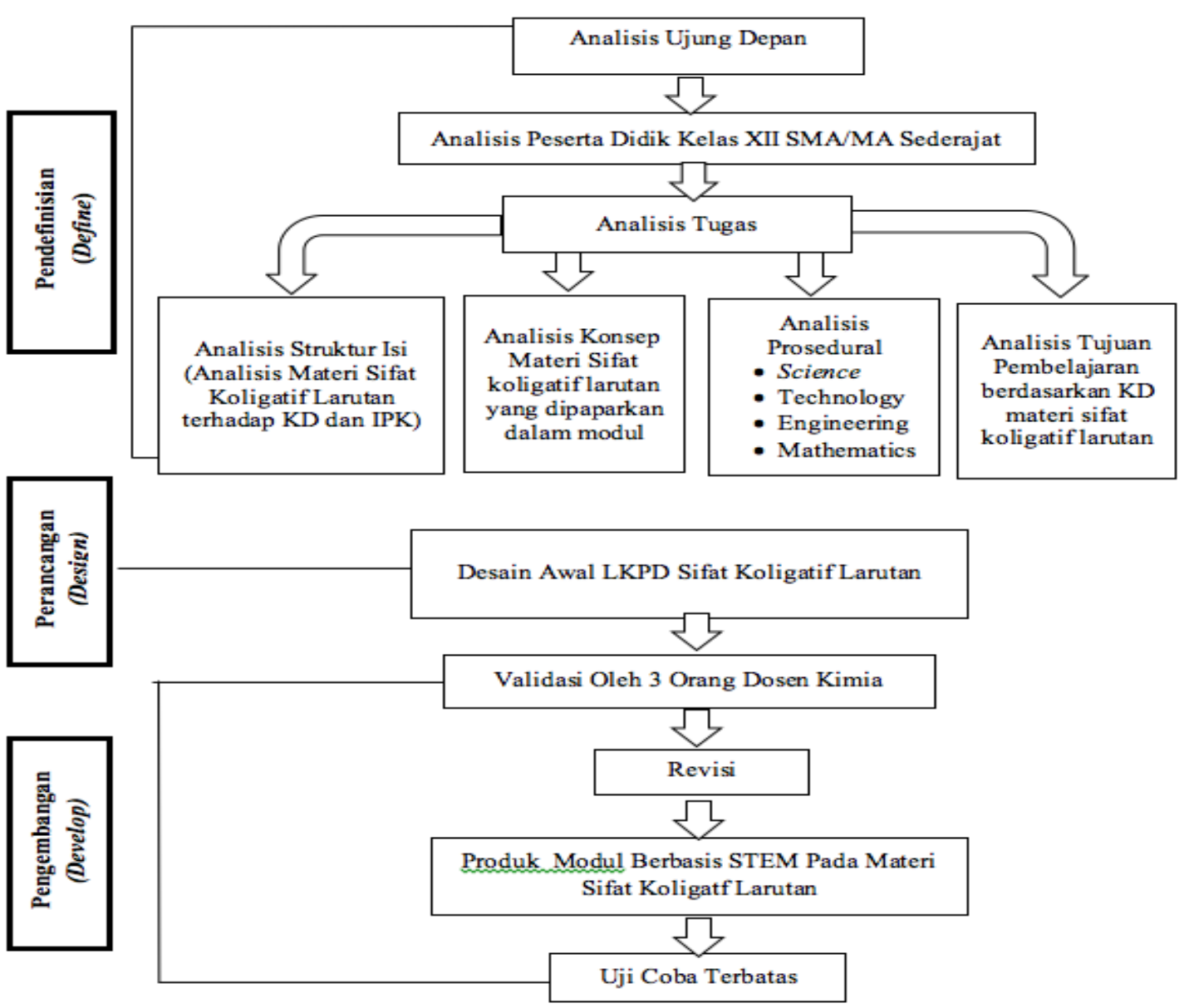

Gambar 1. Alur Pengembangan Modul Sifat Koligatif Larutan Berbasis STEM (Trianto, 2012) 


\section{HASIL DAN PEMBAHASAN}

Produk yang dihasilkan dari penelitian pengembangan ini adalah modul berbasis STEM pada materi Sifat Koligatif Larutan untuk kelas XII SMA/MA, menggunakan pendekatan $R \& D$ (Research and Development) dengan model pengembangan 4-D. MODUL telah dikembangkan melalui tahap pendefinisian (define), perencanaan (design) dan pengembangan (develop).

Tahap analisis dilakukan analisis struktur materi, indikator pencapaian kompetensi dan konsep berdasarkan silabus 2017. Analisis yang dihasilkan yakni menentukan isi modul dengan menganalisis silabus sesuai kurikulum berdasarkan materi yang dikembangkan yaitu sifat koligatif larutan. Analisis materi sifat koligatif larutan berdasarkan kompetensi dasar yang merujuk pada silabus sehingga menghasilkan indikator pencapaian kompetensi (IPK) dan tujuan pembelajaran yang akan dituang ke dalam modul. Tujuan pembelajaran sebagai acuan dalam proses pembelajaran dan juga memfokuskan materi yang akan diajarkan dari IPK dan tujuan pembelajaran didapatkan konsep-konsep utama yang akan diajarkan di dalam modul, selanjutnya digambarkan menjadi pera konsep yang berisikan tentang materi sifat koligatif larutan yang akan dipelajari dalam modul.

Pada tahap perancangan dilakukan dengan penyusunan awal modul yang mencakup penetapan judul, materi modul, latihan dan nilai-nilai STEM dalam modul. Penyusunan modul dilakukan dengan menyusun hasil analisis struktur isi, peta konsep, dan penyusunan judul kegiatan belajar. Berdasarkan analisis Kompetensi Dasar (KD) pada materi sifat koligatif larutan, dapat diketahui banyaknya kegiatan belajar dan judul setiap kegiatan belajar. Modul ini disusun terdiri dari 4 kegiatan belajar yaitu : Kegiatan Belajar I, Kegiatan Belajar II, dan Kegiatan Belajar III dan kegiatan Belajar IV dengan judul berturut-turut adalah penurunan tekanan uap, kenaikan titik didih, penurunan titik beku dan tekanan osmosis.

Tahap pengembangan dilakukan dengan validasi dan revisi sehingga mendapatkan modul berbasis STEM pada materi sifat koligatif larutan yang valid. Validasi modul bertujuan untuk mengetahui kelayakan modul yang akan digunakan dalam kegiatan pembelajaran. Perolehan skor rata - rata validasi LKPD pada tiap aspek dapat dilihat pada Tabel 3. Hasil penilaian modul berbasis STEM oleh validator ditunjukkan pada Gambar 2.

Tabel 3. Persentase skor rata-rata validasi LKPD

\begin{tabular}{l|l|cc}
\hline \multirow{2}{*}{ No } & \multirow{2}{*}{ Aspek Penilaian } & \multicolumn{2}{c}{ Nilai (\%) } \\
\cline { 3 - 4 } & & Validator 1 & Validator 2 \\
\hline 1 & Kelayakan Isi & 72.50 & 80.00 \\
2 & Kelayakan Karakter STEM & 72.91 & 87.50 \\
3 & Kelayakan bahasa & 72.91 & 80.21 \\
4 & Kelayakan penyajian & 79.21 & 90.63 \\
5 & Kelayakan Kegrafisan & 65.00 & 91.25 \\
& Skor Rata-Rata & $\mathbf{7 2 . 5 1}$ & $\mathbf{8 5 . 9 2}$ \\
\hline & Kategori & Cukup Valid & Valid \\
\hline
\end{tabular}

Validasi Aspek Kelayakan Isi memiliki 10 komponen penilaian yang bertujuan untuk menilai ketepatan konsep kimia pada materi sifat koligatif larutan . Komponen modul sesuai dengan KD dan mencakup semua materi sifat koligatif larutan. Skor total validasi I pada aspek kelayakan isi adalah 72,5\% dengan kategori kevalidan cukup baik. Untuk memaksimalkan produk yang dikembangkan diperlukan perbaikan sehingga dihasilkan persentase $80 \%$ pada validasi II dengan kategori kevalidan valid dan layak digunakan.

Validasi Aspek Penyajian memiliki 12 komponen yang bertujuan untuk menilai kualitas penyajian modul berbasis STEM pada materi sifat koligatif larutan. Skor total validasi I pada aspek 
penyajian adalah $79,1 \%$ dengan kategori kevalidan baik dan pada validasi II dihasilkan persentase kelayakan sebesar 90,625\% dengan kategori kevalidan valid dan layak digunakan.

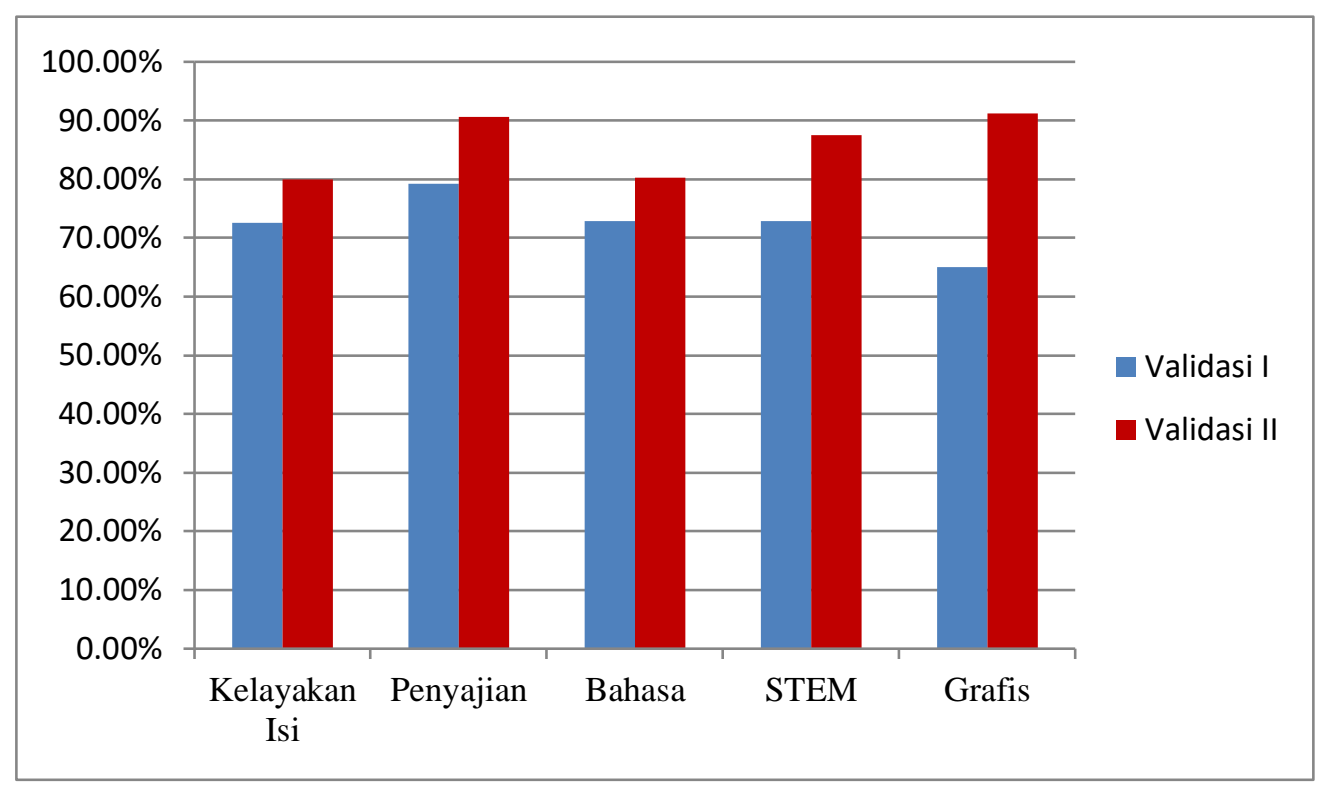

Gambar 2. Hasil penilaian modul berbasis STEM oleh Validasi I dan II

Validasi Aspek Bahasa memiliki 12 komponen penilaian yang bertujuan untuk menilai tingkat keterbacaan dan penggunaan bahasa di dalam modul. Skor total Validasi I pada aspek bahasa adalah 72,915\% termasuk dalam kategori kevalidan baik namun masih perlu dilakukan revisi untuk didapatkan penilaian yang lebih maksimal sehingga pada Validasi II didapatkan skor sebesar 80,205\% dan masuk kategori layak digunakan.

Validasi Aspek STEM memiliki enam komponen penilaian yang bertujuan untuk menilai nilai-nilai STEM yang terkandung di dalam modul. Skor total validasi I pada aspek STEM adalah $72,91 \%$ dengan kategori kevalidan cukup baik dan pada validasi II dihasilkan persentase kelayakan sebesar $87,5 \%$ dengan kategori kevalidan valid dan layak digunakan.

Validasi Aspek Kegrafisan memiliki 20 komponen penilaian yang bertujuan untuk menilai modul secara fisik, ketetapan tata letak, tulisan, gambar/ilustrasi dan desain modul. Skor rata-rata penilaian validator pada validasi I adalah $65 \%$ termasuk dalam kategori cukup baik. Skor rata-rata pada validasi II modul berbasis STEM pada materi sifat koligatif larutan adalah 91,25\%. Validator menilai bahwa kesesuaian kalimat, jenis huruf, kemudian warna serta bingkai tiap-tiap fitur di dalam modul sudah sangat serasi dan tidak mengganggu pengguna untuk membaca modul.

\section{KESIMPULAN DAN REKOMENDASI}

\subsection{Kesimpulan}

Berdasarkan hasil penelitian dapat disimpulkan bahwa: pengembangan modul berbasis STEM pada materi sifat koligatif larutan untuk kelas XI SMA/MA sederajat dilakukan dengan menggunakan desain penelitian 4-D. modul hasil pengembangan divalidasi dan dinyatakan telah memenuhi aspek kelayakan isi, karakteristik STEM, kebahasaan, penyajian dan kegrafisan dengan persentase kelayakan berturut-turut sebesar $80 \%, 90,625 \%, 80,205 \%, 87,5 \%, 91,25 \%$ dengan rata-rata skor $\mathbf{8 5 , 9 1 6 \%}$.dengan kategori kelayakan valid. Uji coba kepada guru diperoleh hasil berada pada kriteria sangat baik dengan persentase rata-rata sebesar $92,1 \%$ 


\subsection{Rekomendasi}

Penelitian pengembangan modul berbasis STEM pada materi sifat koligatif larutan untuk kelas XII SMA/MA sederajat dilakukan baru melalui tahap validitas dan uji coba terbatas kepada guru. Oleh karena itu, peneliti mengharapkan agar modul yang telah dikembangkan ini dapat dilanjutkan pada penelitian selanjutnya yaitu uji coba peserta didik dan tahap uji coba kelompok besar juga tahap penyebaran guna menguji keefektifannya dalam proses pembelajaran dengan menerapkannya ke dalam proses pembelajaran secara langsung.

\section{DAFTAR PUSTAKA}

Almuharomah, F.A., Mayasari, T., Kurniadi. E. 2019. Pengembangan Modul Fisika STEM Terintegrasi Kearifan Lokal "Beduk" untuk Meningkatkan Kemampuan Berpikir Kreatif Siswa SMP. Berkala Ilmiah Pendidikan Fisika. 7(1): 1-10

Andi Prastowo. 2012. Panduan Kreatif Membuat Bahan Ajar Inovatif. DIVA Press. Yogyakarta.

Asmuniv. 2015. Pendekatan Terpadu STEM upaya mempersiapkan sumber daya manusia Indonesia yang memiliki pengetahuan interdispliner dalam menyongsong kebutuhan bidang karir pekerjaan masyarakat ekonomi ASEAN. (online). http://www.vedcmalang.com/pppptkboemlg/index.php/menuutama/listrik-electro/1507-asv9 (diakses pada tanggal 28 Januari 2019)

Depdiknas. 2008. Pengembangan Bahan Ajar. Direktorat Pembinaan Sekolah Menengah Atas Direktorat Jenderal Manajemen Pendidikan Dasar dan Menengah Departemen Pendidikan Nasional. Jakarta.

Irma Suwarma , Astuti Puji dan Nur Endah . 2015. Ballon Powered Car " sebagai media pembelajaran IPA berbasis STEM ( Science Technology Engineering Mathematic ). 8 dan 9 Juni 2015. Prosinding Simposium Naisonal Inovasi dan Pembelajaran Sains. Bandung

Juniarti, Siti Zubaidah dan Supriyono Koes. 2016. STEM : Apa, Mengapa dan Bagaimana?.Prosinding Seminar Nasional Pendidikan Sarjana Pascasarjana UM.

Luthfia Ulva Irmita. 2018. Pengembangan Modul Pembelajaran Kimia Menggunakan Pendekatan Science, Technology, Engineering, and Mathematic (STEM) pada materi Kesetimbangan Kimia. Jurnal Pendidikan Kimia 2(2) : 27-37.Universitas Islam Negeri Raden Fatah. Palembang

Martini, E. 2018. Membangun karakter generasi muda melalui model pembelajaran berbasis kecakapan abad 21. Jurnal Pancasila dan Kewarganegaraan. 3(2): 21-27

Muhammad Dahlan. 2017. Pembelajaran Berbasis Science, Technology, Engineering,andMathematics(STEM).(online) $h t t p: / / w w . e u r e k a p e n d i d i k a n . c o m / 2017 / 03 / p e m b$ elajaran-berbasis-science-technology-engieering-mathematics-STEM.html?m=1. (diakses 29 Februari 2019)

Nidaul Khairiyah. 2019. Pendekatan Science, Technology, Engieering, and Mathematics (STEM) Refrensi Standar untuk melakukan pembelajaran dikelas agar lebih efektif dan lebih efisien. Guepedia. Medan

Sugianto, S.D., Ahied, M., Hadi, W.P., Wulandari. A.Y.R., 2018. Pengembangan modul IPA berbasis proyek terintegrasi stem pada materi tekanan. Journal of Natural Science Education Reseach. 1(1): 28-39

Syahirah, M., Anwar, L., Holiwarni. B. 2020. Pengembangan modul berbasis STEM (science, technology, engineering and mathematics) pada pokok bahasan elektrokimia. Jurnal Pijar MIPA. 15(4): 317-324

Tripripa, A., Amir, H., Rohiat. S. 2020. Pengembangan modul larutan penyangga berbasis pendekatan terpadu STEM (science, technology, engineering and mathematics). ALOTROP, Jurnal Pendidikan dan Ilmu Kimia. 4(1): 16-24

Utami, T.N., Jatmiko, A., Suherman. 2018. Pengembangan Modul Matematika dengan Pendekatan Science, Technology, Engineering, And Mathematics (STEM) pada Materi Segiempat. Desimal: Jurnal Matematika. 1(2); 165-172

Viorita, N., Holiwarni, B., Erviyenni. 2019. Pengembangan modul terintegrasi pendidikan karakter pada materi koloid. Jurnal Pendidikan Kimia Universitas Riau. 4(2): 27-35 
Yuningsih, Y. 2019. Pendidikan kecakapan abad ke-21 untuk mewujudkan Indonesia emas tahun 2045. Jurnal Pedagogik Pendidikan Dasar. 9(1): 135-152 